\title{
Redox chemistry of coenzyme $Q-a$ short overview of the voltammetric features
}

\section{Rubin Gulaboski, Velo Markovski \& Zhu Jihe}

Journal of Solid State

\section{Electrochemistry}

Current Research and Development in Science and Technology

ISSN $1432-8488$

J Solid State Electrochem

DOI 10.1007/s10008-016-3230-7

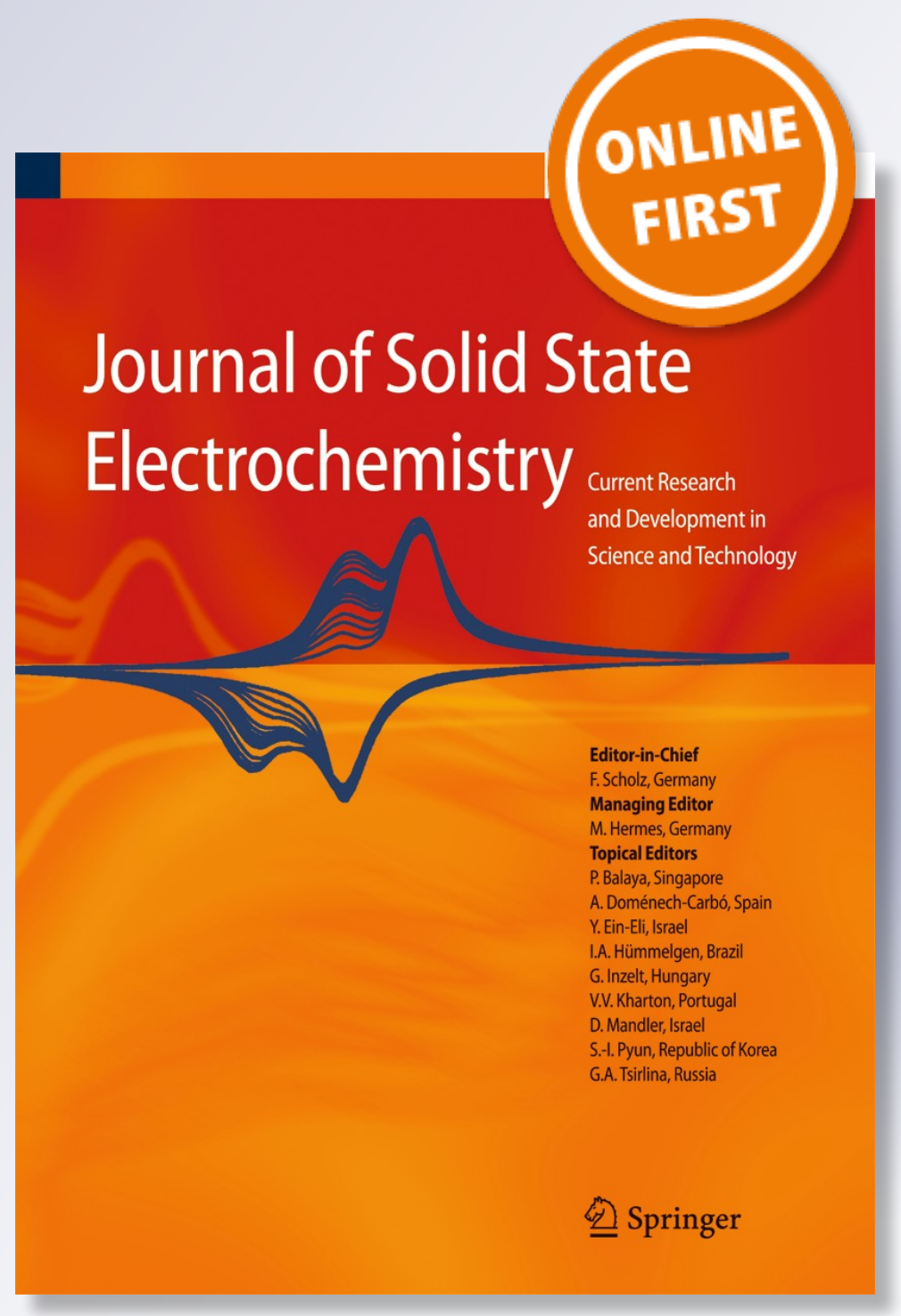

脰 Springer 
Your article is protected by copyright and all rights are held exclusively by SpringerVerlag Berlin Heidelberg. This e-offprint is for personal use only and shall not be selfarchived in electronic repositories. If you wish to self-archive your article, please use the accepted manuscript version for posting on your own website. You may further deposit the accepted manuscript version in any repository, provided it is only made publicly available 12 months after official publication or later and provided acknowledgement is given to the original source of publication and a link is inserted to the published article on Springer's website. The link must be accompanied by the following text: "The final publication is available at link.springer.com". 


\title{
Redox chemistry of coenzyme $Q-$ a short overview of the voltammetric features
}

\author{
Rubin Gulaboski $^{1} \cdot$ Velo Markovski $^{1} \cdot$ Zhu Jihe $^{1}$
}

Received: 6 March 2016 /Revised: 23 April 2016/Accepted: 26 April 2016

(C) Springer-Verlag Berlin Heidelberg 2016

\begin{abstract}
Quinones constitute a big family of organic redox active compounds that are overwhelmingly involved in important physiological processes. The most important members in the class of quinones are, indeed, the plastoquinones and the coenzyme Q (CoQ) derivatives. Voltammetry of coenzyme $Q$ family members attracts significant attention since 50 years ago. In this work, we refer to some of the most important voltammetric features of coenzyme Qs studied in aprotic and in aqueous media. While the redox chemistry of coenzyme Q members in non-aqueous aprotic organic solvents can be described by two consecutive one-electron transfer steps, more complex situation exists in the voltammetry of coenzyme Qs performed in aqueous media. Although it has been claimed for a while that the voltammetric processes of coenzyme Qs in aqueous solutions proceed via formation of semiquinone radical intermediate species, it has been recently proven that this can be not completely true. Intensive voltammetric and spectroscopic studies of coenzyme Q systems in buffered and non-buffered aqueous media revealed that hydrogen bonding between electrochemically created $\mathrm{CoQ}$ species and the water molecules plays an important role in stabilizing electrochemically generated species of these systems. We also pay attention to the amazing redox chemistry of coenzyme Qs in strong alkaline media, while we refer to the chemical features of novel coenzyme Q derivatives obtained under such conditions. Hints are presented about the
\end{abstract}

Dedicated to the 65 th birthday of our great friends and collaborators Dr. Milivoj Lovric and Dr. Sebojka Komorsky Lovric

Rubin Gulaboski

rubin.gulaboski@ugd.edu.mk

1 Faculty of Medical Sciences, Goce Delcev University, Stip, Macedonia antioxidant capacity of some of the novel hydroxylated coenzyme Q systems. Also, the possibility of these systems to bind and transfer earth-alkaline cations across biomimetic membranes is shortly elaborated. In the end, we refer to some relevant theoretical works that describe closely the voltammetric behavior of various coenzyme Q systems. We believe that this short review will contribute towards better understanding of the amazing chemistry of coenzyme Q derivatives.

Keywords Quinones · Voltammetry · Mitochondrial electron transfer chain $\cdot$ Antioxidants $\cdot$ Embelin

\section{Introduction}

Quinones are probably the most abandoned class of redox active organic compounds involved in many important chemical and physiological processes $[1,2]$. Many quinones are found in plenty of bacteria and various plants, and they are ubiquitous in all living systems [3]. Vitamin E, coenzyme Qs, plastoquinone, naphthoquinones, anthraquinones, and plenty of polyphenols (flavonoids and stilbenes) are just some representatives belonging to the class of quinones. The most important members of the quinone family are, indeed, Coenzyme $\mathrm{Q}_{10}(\mathrm{CoQ} 10)$ and plastoquinone. These two benzoquinones play fundamental roles in vital biological functions such as oxidative phosphorylation and mitochondrial electron transfer processes. Their function as redox mediators in the crucial energetic processes like photosynthesis and respiration is essential to life on Earth. As we know, the major pathway for creating energy in all living systems is via the mitochondrial electron transfer chain (METC) that takes place in the inner membranes of the mitochondria. In the METC, electrons and protons are shuttled between various redox 
proteins to reach the final target- the oxygen molecules. The final output of this complex system of redox transformations in METC is reduction of oxygen to water. This reaction is followed by consecutive formation of adenosine triphosphate (ATP), whose one-phosphate group dissociation releases thermal energy that is crucial for supporting of many physiological processes. Embedded in the inner mitochondrial membrane is the compound Coenzyme $\mathrm{Q}_{10}$ (or Ubiquinone 50) that mediates the transfer of electrons between complexes I, II, and III in the METC, while also transferring protons across the mitochondrial membrane. During the occurrence of the electron and proton transfer reactions in the METC, Coenzyme $\mathrm{Q}_{10}$ turns between fully oxidized form-quinone and fully reduced form-quinol (or ubiquinol). Next to this crucial role in the cell energy creation, there are lots of studies dedicated to many other functions of Coenzyme $\mathrm{Q}_{10}$ in the living cells [4, 5]. It is well known that Coenzyme $\mathrm{Q}_{10}$ occurs in all subcellular membranes, while having a very important role in functioning of many membrane oxido-reductase systems such as mitochondria, Golgi apparatus, lysosomes, and plasmalemma $[1,5]$. In these systems, Coenzyme $\mathrm{Q}_{10}$, via its redox chemistry, influences many pathways in the cells, ranging from pro-oxidant to antioxidant activities (free-radical generation and scavenging of free radicals) and modulating cellular pathology [6-8]. Our focus in this short review is to bring the readers some important insights into the redox features of coenzyme Q family members studied by voltammetric techniques and to emphasize several recent findings in respect to their chemical reactivity. Although the redox chemistry of coenzyme Qs is a subject of interest for over 50 years, many new aspects of their amazing chemistry still emerge. We hope that this work will help readers to understand some of the most important features of CoQs (Scheme 1).

\section{Redox chemistry of coenzyme Qs in non-aqueous media}

In the family of quinones, the coenzyme Q compounds (CoQs) are, indeed, the most important biological systems. Although it has been thought for a while that these systems exhibit superficially simple redox behavior, this, in fact, has been proven not so simple. The redox chemistry of coenzyme Qs can be extremely complex, and many aspects of their electrochemical behavior are not well understood even nowadays. The simplest voltammetric scenario of the redox transformations of coenzyme Qs one finds is if these biological systems are studied in organic solvents, but in absence of proton-donating substances. Numerous works focused on the voltammetric features of coenzyme $Q$ family members have revealed that the redox chemistry of these systems depends significantly on the solvent medium and the proton availability in the electrolyte system [see 2 and 9 for more details]. Except the simplest member of the coenzyme Q family, i.e., Coenzyme Q0, which is a nicely water-soluble substance, all the other coenzyme Qs are hardly water-soluble substances. Therefore, in majority of the works found in the literature, the redox chemistry of Coenzyme $\mathrm{Q}_{1}$ to Coenzyme $\mathrm{Q}_{10}$ members has been studied in non-aqueous media. Many studies of coenzyme Q members performed in organic solvents in the absence of protons reveal that a stepwise twoelectron reduction of these compounds occurs [9-12]. In the first step, a semi-quinone radical anion of CoQs is formed $\left(\mathrm{CoQ}^{-}\right)$, while in the second step a dianion is obtained $\left(\mathrm{CoQ}^{2-}\right)$. Many of these scenarios are thoroughly elaborated in the literature, while various authors agree that the redox chemistry of coenzyme Qs in organic solvents in the absence of protons can be represented by the following redox scheme:

$\mathrm{CoQ}+1 \mathrm{e}^{-} \leftrightarrow \mathrm{CoQ}^{-}+1 \mathrm{e}^{-} \leftrightarrow \mathrm{CoQ}^{2-}$

The redox chemistry of CoQs dissolved in organic electrolyte solutions in the absence of protons is mainly portrayed via two distinct voltammetric signals controlled by diffusion (see Fig. 1).

Addition of proton-donating compounds in the electrochemical cell containing aprotic organic solvent brings exceptional complexity in the redox features of CoQ systems. As explained in several relevant works [2, 9-14], in such scenario, nine CoQ species can exist (theoretically) in the system, while various equilibriums among them are also possible (see Scheme 2).

Indeed, what is missing in all scenarios similar to those given in Scheme 2 is the possibility of CoQ's radical reaction that commonly leads to dimerization of two CoQ radical species. In a mixture of acetonitrile and acetic acid, for example, it has been found that Coenzyme $\mathrm{Q}_{10}$ exhibits two consecutive one-electron-one-proton transfer steps [15]. The author of [15] has also found that the redox process of Coenzyme $\mathrm{Q}_{10}$ in such environment proceeds via creation of unstable semiquinone radical. This has also been confirmed when CoQ10 was studied in glacial acetic acid solution [16]. Similar findings about coenzyme Q's redox conversion are also reported elsewhere in many other works performed in

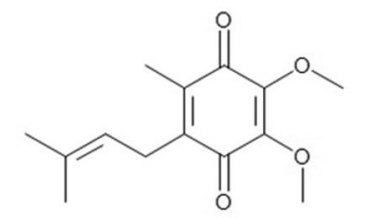

10

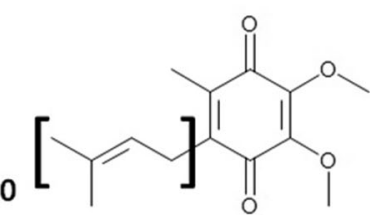

Scheme 1 Structural formulas of Coenzyme Q0 (left), Coenzyme $\mathrm{Q}_{1}$ (middle), and Coenzyme $\mathrm{Q}_{10}$ (right)

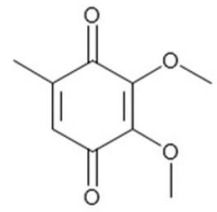




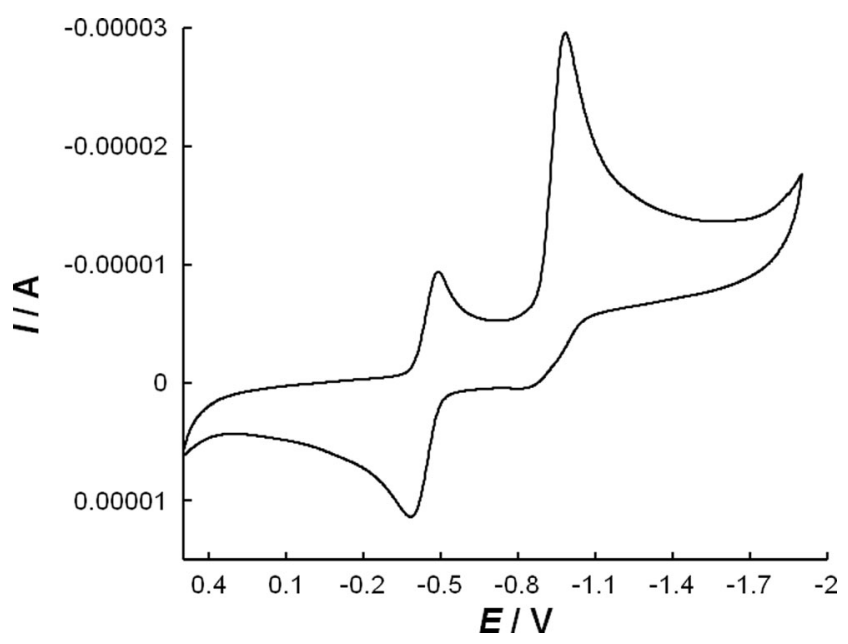

Fig. 1 Cyclic voltammogram of $0.5 \mathrm{mmol} / \mathrm{L}$ Coenzyme $\mathrm{Q}_{1}$ recorded in acetonitrile $(0.05 \mathrm{mmol} / \mathrm{L}$ tetrabutylammonium perchlorate was used as a supporting electrolyte) at a glassy carbon working electrode. Scan rate was $20 \mathrm{mV} / \mathrm{s}$. The peak at less negative potentials corresponds to the reaction $\mathrm{CoQ}+1 \mathrm{e}^{-} \leftrightarrow \mathrm{CoQ} \bullet-$, while the voltammetric signal at more negative potentials is due to reaction $\mathrm{CoQ} \cdot-+1 \mathrm{e}^{-} \leftrightarrow \mathrm{CoQ}^{2-}$

waterless organic solvents, regardless of the nature of the aprotic organic solvent used $[2,9,10,12,13,17-20]$. Itoh et al. [21] reported a rather complex behavior of plastoquinone, observing three reduction and four oxidation peaks in the cyclic voltammograms recorded in aprotic organic solvents. Some of the signals observed are due to the $\mathrm{CoQ}$ dimmers formed during the course of the voltammetric experiment. Existence of several semiquinone radicals is reported in this work [21], one of them having potential to bind calcium cations. It is worth mentioning that many of the theoretically predicted CoQ species described in Scheme 2 of this work have never been detected by studying CoQs in organic waterless media. Only some of the species in the two upper lines of Scheme 2 as well as $\mathrm{CoQH}_{2}$ species are experimentally detected and reported.
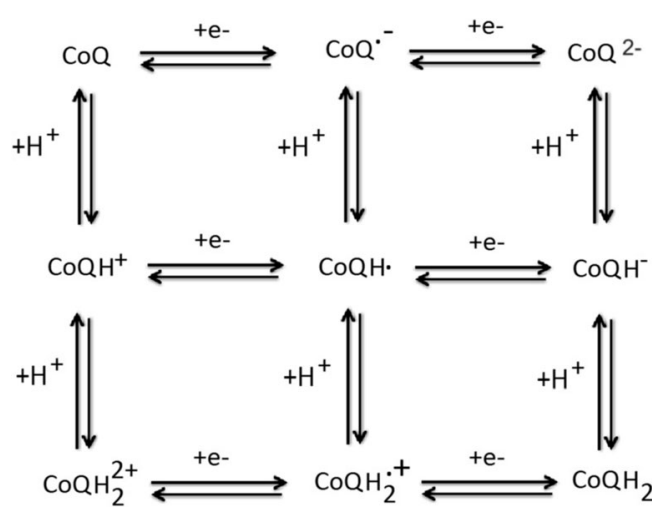

Scheme 2 Possible redox transformations and equilibria in the coenzyme Q's redox chemistry $[2,13]$

\section{Redox chemistry of coenzyme $Q$ in aqueous media}

Due to the poor solubility of CoQs in water, more complex scenarios are applied to study these systems in aqueous environment. Except with Coenzyme Q0, and to some extent with Coenzyme $\mathrm{Q}_{1}$, it is quite difficult to perform common voltammetric experiments with native forms of higher CoQ members in acidic, neutral, or slightly alkaline water solutions at solid working electrodes. Indeed, the reason for this is the poor water solubility of the higher members of the coenzyme Q family. Many of the obstacles met by the voltammetric determination of coenzyme Qs dissolved in aqueous environment are described in the work of Turkowicz et al. [22]. The authors of [22] refer to the adsorption of CoQs and the blocking of the active surface area of the working electrode as major obstacles in the experiments of coenzyme Qs performed from water solutions. Indeed, additional obstacle is seen in chemical features of the long isoprenoid chains. This isoprenoid chain is considered as insulating part of the CoQ's moiety that hinders the electron transfer between the working electrode and the redox active site(s) of the CoQs. However, there are some reports in the literature that refer to achieving a direct determination of Coenzyme Q10 even from pure water buffers in voltammetric experiments by using glassy carbon as a working electrode [23]. In [23], the authors describe a simple and rapid voltammetric method for quantification of coenzyme $\mathrm{Q}_{10}$ dissolved in a phosphate buffer solution $(\mathrm{pH}$ 6.86). The authors of [23] report to existence of an electrochemically irreversible and diffusionally controlled single process of CoQ10 recorded under such conditions. They claim that they succeeded to quantify CoQ10 in submillimolar concentrations. Yet, it is not clear how the authors achieved to dissolve such a significant concentration of Coenzyme Q10 in pure water buffers. Lemmer et al. [24] describe an elegant strategy of studying lipophilic CoQs by using an Au-working electrode modified with lipophilic thiols in which CoQ was embedded. Under such circumstances, the voltammetric features of Coenzyme $\mathrm{Q}_{2}$ were studied in $\mathrm{pH}$ range from 2.50 to 12.50 . Moreover, in that work [24], the authors go one step further and they report to the kinetic parameters of electron transfer steps. In such an arrangement, the authors report that $\mathrm{CoQ}_{2}$ undergoes common redox transformation as described in Reaction (I) of this work. A bit different scenario for studying the voltammetric features of CoQ10 at solid electrodes in water media is reported in [25]. In that work [25], Coenzyme $\mathrm{Q}_{10}$ and plastoquinone were incorporated in a lipid bilayer composed of dimyristoyl phosphatidylcholine that was supported by vesicle fusion. The redox properties of CoQ10 and plastoquinone were studied in a wide $\mathrm{pH}$ range. Only above $\mathrm{pH}$ of 13 did the authors report a reversible redox behavior of these substrates. Below $\mathrm{pH}$ of 12 , severe kinetic hindrances are reported that, as the authors claimed, were due to the slow kinetic of electron transfer steps. Similar scenario 
for studying the lipophilic coenzyme Qs and CoQ oxidoreductase enzymes is also reported in [26]. One can find in the recent book an important source that reports to different methodologies applied for achieving better strategies for voltammetric study of Coenzyme $\mathrm{Q}_{10}$ [27]. Using some of the strategies explained in [27], various authors report on designing voltammetric sensors based on CoQ10 redox features. For example, the redox chemistry of Coenzyme $\mathrm{Q}_{10}$ embedded in the lipid membranes has been explored to construct some elegant sensors in the recent years. In the work of Ru et al. [28], a CoQ10-modified electrode was explored for designing a nano-to-micromolar sensor for glutathione detection. The sensor was constructed by using its gel form that was mixed with multi-walled carbon nanotubes/ionic liquid. In another work [29], the authors have used CoQ10 supported in lipid bilayers to construct a sensor for acetylcholine detection. The features of several other CoQ-based voltammetric sensors are reported elsewhere [30].

Getting insight into the redox features of Coenzyme $\mathrm{Q}_{10}$ by performing voltammetry on solid electrodes is quite difficult to be achieved. A better option for this purpose is, indeed, the use of the lipophilic mercury as a working electrode. As highly lipophilic compounds, most of the higher members of the CoQ family adsorb significantly at the surface of the working mercury electrode. This phenomenon allows achieving preconcentration of the CoQs on the mercury electrode, while common voltammetric experiments can be performed in such scenario. Many authors report on the mechanistic studies of various coenzyme Qs from an aqueous environment at mercury electrode [2, 9, 31, 32]. In the works [31, 32], authors observed common voltammetric features of the coenzyme Qs as reported elsewhere $[2,9,33]$. In the work of Gordillo and Schiffrin [32], instability of the voltammograms of CoQ10 has been reported in strong alkaline media. However, the authors did not pay more efforts to clarify this phenomenon. More relevant aspects related to the coenzyme Q's redox chemistry in aqueous media can also be found in [34-40].

\section{Voltammetry of coenzyme Qs in buffered and non-buffered aqueous media}

Several recent comprehensive studies related to the voltammetric features performed with water-soluble quinones and coenzyme Qs in buffered and non-buffered aqueous media probably gave best explanations about the disputed redox behavior of these systems [41-44]. In fact, many authors claimed that the redox chemistry of coenzyme Qs and quinones from water solutions is always linked to a mechanism in which free radical intermediates are involved [see 2, 9, and 33, for example]. However, with the results published in the last 8 years, the question about the redox chemistry of quinones in aqueous solutions seems to be a step closer to the final solution. The initial study of Smith et al. [41] brought a new light in explaining the complex redox chemistry of coenzyme Qs in water. As explained in [41], and later on in several recent works $[42,43]$, the two electron-two proton voltammetric behavior of coenzyme Qs $\left(\mathrm{CoQ}+2 \mathrm{e}^{-}+2 \mathrm{H}^{+}\right.$ $\leftrightarrow \mathrm{CoQH}_{2}$ ) can only be seen in buffered aqueous systems, in regions of $\mathrm{pH}$ between 2.0 and 11.0, or in very strong acidic media. Under such circumstances, a single pair of voltammetric peaks is observed whose mid-peak potential is sensitive to $\mathrm{pH}$, shifting by $-60 \mathrm{mV} / \mathrm{pH}$. The entire process exhibits strong kinetic hindrances in the region of $\mathrm{pH}$ between 2.5 and 10.5 (see Fig. 2, the cyclic voltammograms of Coenzyme Q0, for example). These are portrayed via a huge peak-to-peak separation that increases from $450 \mathrm{mV}$ (at scan rate of $10 \mathrm{mV} / \mathrm{s}$ ) to over $650 \mathrm{mV}$ (at scan rate of $200 \mathrm{mV} / \mathrm{s}$ ). It has been a question for a while to determine whether the observed kinetic hindrances are due to the slow electron transfer or due to the slow proton transfer step. Although many authors claimed that this behavior is due to the slow rate of the heterogeneous electron transfer step [2, 9, 12,33], it seems that the protonation step is crucial for these features in the CoQ voltammetry. This will be shortly elaborated later on in this chapter.

The voltammetry of water-soluble CoQs and quinones in non-buffered aqueous media is much more complex compared with that in buffered aqueous solutions. Depending on $\mathrm{pH}$ and the $c(\mathrm{CoQs}) / c\left(\mathrm{H}^{+}\right)$ratio, at least three different scenarios can be observed with coenzyme Q systems dissolved in non-buffered aqueous media in $\mathrm{pH}$ region between 1.0 and 11.0. In the cyclo-voltammetric experiments, roughly in the $\mathrm{pH}$ region between 1.0 and 2.5 , a single pair of peaks exists. The mid-peak potential $E_{\text {mid,p }}$ vs. pH dependence in this region of $\mathrm{pH}$ is about $-60 \mathrm{mV} / \mathrm{pH}$. However, in the region from $\mathrm{pH}=2.50$ to $\mathrm{pH}=4.00$ (assuming a $0.5-\mathrm{mmol} / \mathrm{L}$ concentration of coenzyme Qs in the electrochemical cell), there are two distinct processes at the cyclic voltammograms. The mid-peak potential $\left(E_{\mathrm{mid}, \mathrm{p} 1}\right)$ of the signal appearing at more positive potentials is a linear function of $\mathrm{pH}$ with a slope

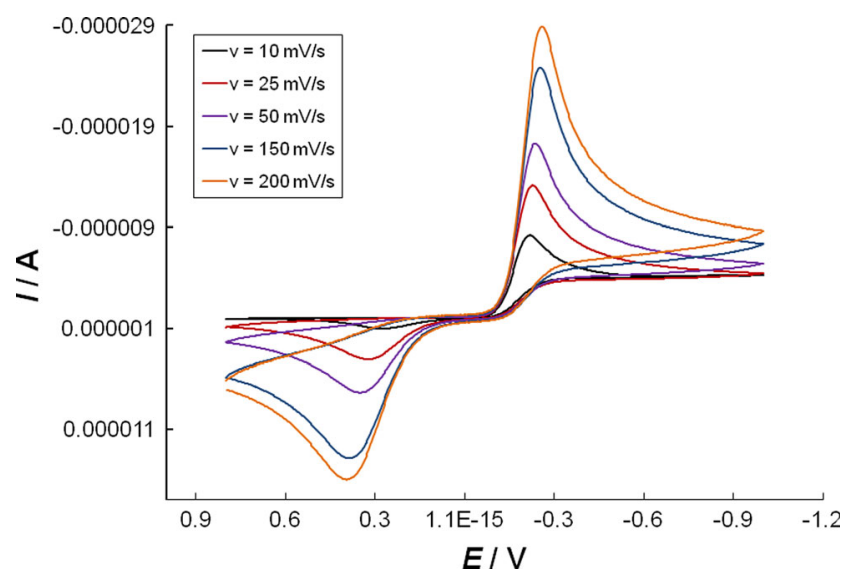

Fig. 2 Cyclic voltammograms of Coenzyme Q0 recorded in ammonia buffer $(\mathrm{pH}=7.40)$ as a function of the applied scan rates. $c$ (Coenzyme Q0) was $0.5 \mathrm{mmol} / \mathrm{L}$ 
of about $-60 \mathrm{mV} / \mathrm{pH}$. However, the second signal positioned at more negative potentials shifts linearly in a negative direction for about $-30 \mathrm{mV} / \mathrm{pH}$. In non-buffered water solutions having $\mathrm{pH}$ in the region between $\mathrm{pH}=4.0$ and $\mathrm{pH}=4.70$, the intensity of the second signal (at more negative potentials) decreases in the course of a slight increase of $\mathrm{pH}$. Concomitantly, a new reversible voltammetric signal appears (in the potential region between the first two peaks) that gains in intensity by increasing $\mathrm{pH}$. Above a $\mathrm{pH}$ of about 5.0, this new (third) pair of peaks is the only one existing in the voltammetric output. The intensity of this new voltammetric pair of peaks is virtually constant in the $\mathrm{pH}$ region from 5.50 to 10.5. However, what is more intriguing is that the mid-peak potential of this third voltammetric peak gets unaffected by $\mathrm{pH}$. By making comprehensive voltammetric, electron paramagnetic resonance (EPR), and UV-Vis studies [42, 43], it has been confirmed that the water-soluble CoQs undergo three different redox transformations in non-buffered aqueous media that can be represented by the following reaction schemes:

As it is presented in Scheme 3, next to the two electron$2 \mathrm{H}^{+}$reduction of coenzyme Qs to a hydroquinone form

a) $E_{\text {mid,p }} v s$. $\mathrm{pH}$ dependence is $-60 \mathrm{mV} / \mathrm{pH}$ for $c($ CoQ's $) \ll c_{\circ}\left(\mathrm{H}^{+}\right)$.

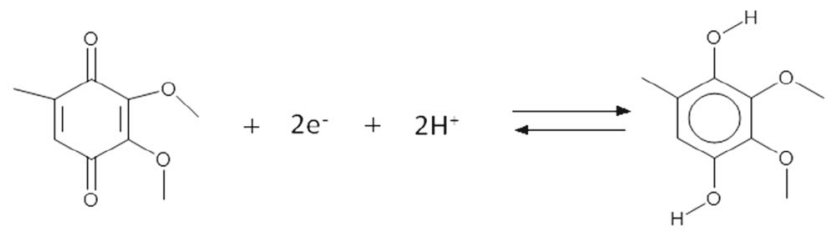

b) $E_{\text {mid,p }} v s$. $\mathrm{pH}$ dependence is $-30 \mathrm{mV} / \mathrm{pH}$ for $c_{\circ}(\mathrm{CoQ}$ 's $) \sim c\left(\mathrm{H}^{+}\right)$.

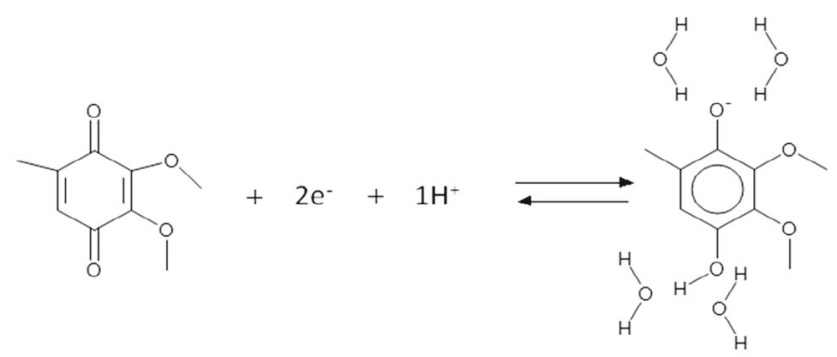

C) $E_{\text {mid,p }} v s . \mathrm{pH}$ dependence is $0 \mathrm{mV} / \mathrm{pH}$ for $c_{0}\left(\mathrm{Co}_{\mathrm{Q}}\right.$ 's $)>c\left(\mathrm{H}^{+}\right)$.

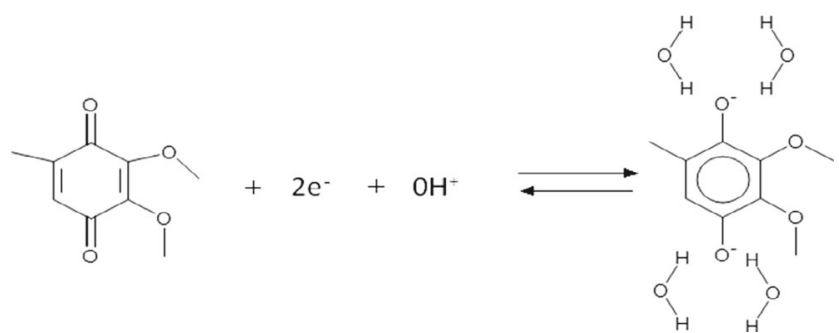

Scheme 3 Redox transformation of Coenzyme Q0 in non-buffered aqueous media. a $E_{\text {mid,p }}$ vs. $\mathrm{pH}$ dependence is $-60 \mathrm{mV} / \mathrm{pH}$ for $c(\mathrm{CoQ})$ $<<c_{\mathrm{o}}\left(\mathrm{H}^{+}\right)$. b $E_{\text {mid,p }}$ vs. pH dependence is $-30 \mathrm{mV} / \mathrm{pH}$ for $c_{\mathrm{o}}(\mathrm{CoQ}) \sim c\left(\mathrm{H}^{+}\right)$. c $E_{\text {mid,p }}$ vs. $\mathrm{pH}$ dependence is $0 \mathrm{mV} / \mathrm{pH}$ for $c_{\mathrm{o}}(\mathrm{CoQ})>c\left(\mathrm{H}^{+}\right)$ (situation a), there are two more scenarios in which monoanionic (b) and dianionic (c) forms of coenzyme Qs are created. It has been reported that the stabilization of the monoanionic and dianionic coenzyme $\mathrm{Q}$ species was achieved by hydrogen bonding with the water molecules [41-43]. Indeed, as described in [18, 41-43], hydrogen bonding, alongside the protonation steps, is a fundamental factor that controls the potentials and mechanisms in the reduction of coenzyme Qs. All these situations of the voltammetric behavior of Coenzyme Q0 in non-buffered aqueous media (a nicely water-soluble coenzyme Q simplest member) are shown in Scheme 3. Several recent studies [41-43] also revealed that no radical reactions take place in voltammetry of watersoluble quinones in $\mathrm{pH}$ regions from 1.0 to 11.0 , as it has been thought for a while $[2,33]$. Contrary to the situation in buffered aqueous media, where one sees strong kinetic hindrances in the cyclic voltammograms (see Fig. 2 in this work, for example), cyclic voltammograms of Coenzyme Q0 at $\mathrm{pH}$ of 7.00 show almost no kinetic obstacles (see Fig. 3). Recall that the voltammograms in Fig. 3 depict the following situation:

$\mathrm{CoQ}+2 \mathrm{e}^{-}+0 \mathrm{H}^{+} \leftrightarrow \mathrm{CoQ}^{2-}$

Therefore, since no protons are involved in the entire redox process (II), it is reasonable to assume that the kinetic constraints seen in the cyclic voltammograms of CoQs met in buffered media (Fig. 2) are mainly due to the slow proton transfer step. This is another point to be emphasized in the redox chemistry of CoQs, which differs from what is given in the literature $[2,9,31-33]$. Various authors claim that the protonation is a fast process in the quinone redox chemistry, and the kinetic constraints met in the voltammetric behavior of quinones are due to the slow heterogeneous electron transfer step $[2,9,10,13]$. Features of the voltammograms given in Fig. 3 throw a new light to resolve the question about the rate

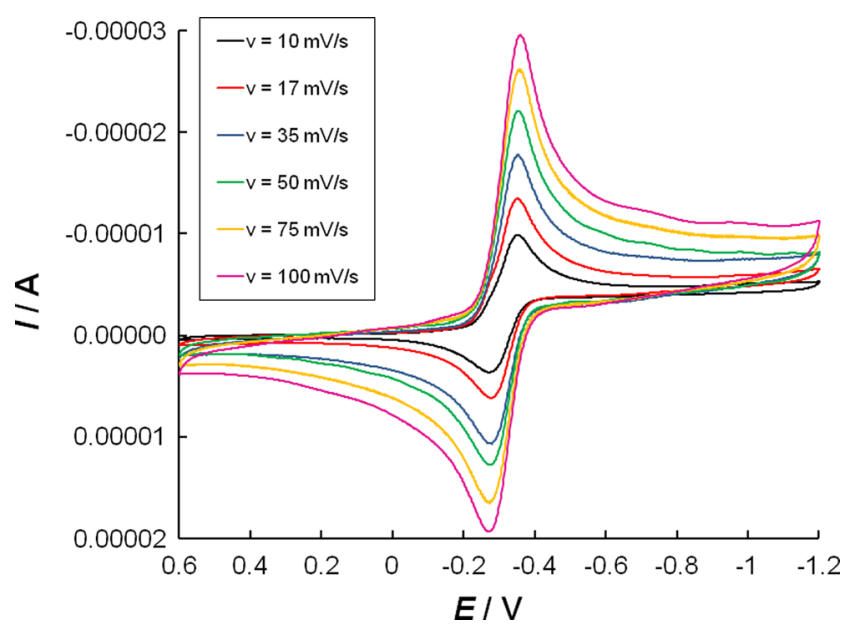

Fig. 3 Effect of the scan rate to the features of the cyclic voltammograms of $0.1 \mathrm{mmol} / \mathrm{L}$ Coenzyme Q0 recorded at $\mathrm{pH}$ of 7.00 in non-buffered aqueous media 
of the protonation steps by the redox chemistry of $\mathrm{CoQ}$ systems. Quite different phenomena are observed when coenzyme Qs are observed in strong alkaline solutions (in aqueous solutions with $\mathrm{pH}$ above 11.50).

\section{Recent findings on coenzyme Q's reactivity in alkaline media}

As shortly mentioned in the work of Gordillo and Schiffrin published more than 20 years ago [32], a sort of chemical instability of CoQ10 has been observed, when it was studied at mercury electrode at $\mathrm{pH}$ above 12.50 . However, in their work [32], the authors did not pay too much attention to this phenomenon. Even recently, the authors of $[42,43]$ have studied extensively the chemistry of several coenzyme Qs in a strong alkaline environment. By exploring HPLC MS, EPR, voltammetric, NMR, and UV-Vis experiments, it has been confirmed that many hydrophilic as well as the highly lipophilic coenzyme Qs undergo significant structural changes in a strong alkaline environment. Via a complex radical reaction pathway (see schemes in 42 and 43), one or both of the methoxy groups $\left(-\mathrm{O}-\mathrm{CH}_{3}\right)$ from the CoQ structures are cleaved under the attack of the $\mathrm{OH}^{-}$anions. This happens in all coenzyme Qs having no single unsubstituted place at the quinonic ring. As a consequence, monosubstituted or disubstituted hydroxyl derivatives of coenzyme Qs are obtained. The newly obtained hydroxyl CoQ derivatives show relatively higher hydrophilicity than their parent compounds. Since the radical reactions are quite fast in $\mathrm{pH}$ above 12.50 , formation of CoQ dimmers also happens $[42,43]$. The complex radical reaction can be quenched by making re-titration (with some strong inorganic acid) to neutral, acidic, or slightly alkaline $\mathrm{pHs}$. However, if there is at least one unsubstituted place in the structure of the quinone ring of CoQs, then only one methoxy group can be cleaved and it can be replaced by one $\mathrm{OH}$ group [43]. In addition, one or two of the unsubstituted sites of the quinone ring of such CoQ derivatives can be substituted by $\mathrm{OH}$ group(s). The hydroxyl derivatives of coenzyme Qs obtained under such circumstances show strong affinity to bind (and some derivatives even to transfer) earth-alkaline cations. Moreover, they show much higher antioxidative potential than the reduced forms of their parent compounds. The reactions of CoQs in alkaline media are seen as a simple method for synthesizing hydroxy $\mathrm{CoQ}$ derivatives $(\mathrm{OH}-\mathrm{CoQ})$ with significantly improved water solubility. These new $\mathrm{OH}-$ CoQs can be used as systems for metal binding and efficient scavengers of free radicals $[42,43]$.

\section{Metal-binding properties of coenzyme Qs}

Various authors have attempted to find out whether native coenzyme Qs have a potential to bind metal cations [see for example 2, 9, 18, 24, 33]. However, most of their efforts were without success. Recently, it has been shown that the hydroxyl derivatives of CoQs obtained via reaction in alkaline media posses a pronounced affinity to bind earth-alkaline cations $[42,43,45]$. Indeed, the presence of proton-donating $\mathrm{OH}$ groups in their structure opens up a way to existence of anionic forms of these hydroxylated CoQ forms in neutral media. Upon the electrochemical reduction, a huge electronic density exists in the structures of the hydroxyl CoQs. Existence of such negatively charged patterns in CoQ structures is quite a suitable platform for interacting with highly positive cations. It has been reported that moderate-to-strong complexes are created between hydroxyl derivatives of CoQ1, $\mathrm{CoQ} 0$, and CoQ10 and the cationic forms of $\mathrm{Ca}, \mathrm{Sr}, \mathrm{Mg}$, and $\mathrm{Ba}[42,43]$. Moreover, the hydroxylated form of CoQ10 was able even to transfer $\mathrm{Ca}^{2+}$ cations across lipid biomimetic membranes [42]. A similar feature has also been observed by another artificial lipophilic coenzyme Q-like derivative named 2-palmitoylhydroquinone [45]. It is worth mentioning that all efforts aiming to show whether hydroxylated forms of CoQs are able to bind monocharged cations failed. A set of representative cyclic voltammograms showing the potential of the dihydroxyl $\mathrm{CoQ} 0$ to make complexes with $\mathrm{Ca}^{2+}$ cations is given in Fig. 4.

\section{Antioxidant properties of coenzyme Qs}

The reduced forms of native coenzyme $\mathrm{Q}$ family members are known as good antioxidants since long ago [1-3, 9, 46, 47]. As we know, CoQs are able to protect the cell membranes of the destructive lipid peroxidation processes. Due to their role in reducing the damaging effects of the highly reactive free radicals, coenzyme Q-based antioxidants are seen as

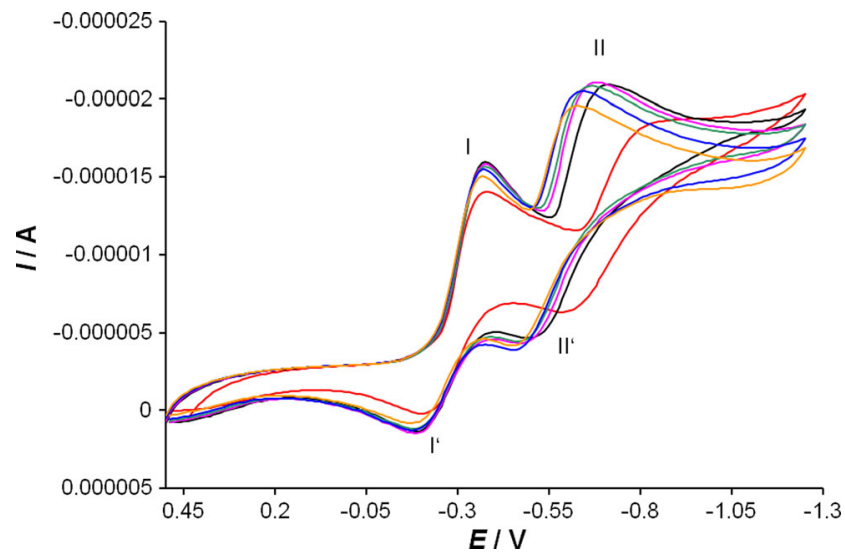

Fig. 4 Cyclic voltammograms of $0.1 \mathrm{mmol} / \mathrm{L}$ Coenzyme Q0 recorded at $\mathrm{pH}$ of 7.00. Effect of the $\mathrm{Ca}^{2+}$ concentration: $c\left(\mathrm{Ca}^{2+}\right) / \mathrm{mmol} / \mathrm{L}=0$ (red curve), 1, 3, 5, 20, and 50 (orange curve). Coenzyme Q0 was initially in contact with $0.1 \mathrm{~mol} / \mathrm{L} \mathrm{NaOH}$ for 45 and afterwards re-titrated to $\mathrm{pH}$ of 7.00 with $5 \mathrm{~mol} / \mathrm{L} \mathrm{HCl}$. Peak I-I' is from the native form of Coenzyme Q0 (insensitive to $\mathrm{Ca}^{2+}$ concentration), while peak II-II' originates from the dihydroxy form of Coenzyme Q0 (sensitive to $\mathrm{Ca}^{2+}$ concentration). Scan rate was $50 \mathrm{mV} / \mathrm{s}$ 
indispensible systems that protect the occurrence of many physiological processes in all living organisms. The potential of acting of various coenzyme $\mathrm{Q}$ antioxidants toward different targets (reactive oxygen species ROS) is described in several review works and books [20,47-53]. Indeed, the antioxidant potential of all coenzyme Qs depends significantly on the nature of the substituents existing in their structural pattern $[2,9,33]$. In general, the presence of groups with electron withdrawing abilities $\left(\mathrm{OH}, \mathrm{Cl}, \mathrm{I}, \mathrm{F}, \mathrm{NO}_{2}\right)$ in the structure of CoQ derivatives increases significantly their potential as antioxidants. In recent experiments with hydroxyl derivatives of coenzyme Qs $[42,43]$, it has been shown that these substances have much higher potential as antioxidants than the reduced forms of their parent compounds. Moreover, in experiments with macrophage cells, it has been shown that the hydroxyl coenzyme Q derivatives have antioxidant potentials similar to that of vitamin C. Indeed, the unique amphiphilic structures of the hydroxyl coenzyme Qs make them very suitable to act as antioxidants on both sides of the biological membranes. In our recent works $[42,43]$, new voltammetric methods have been developed to assess the antioxidant potential of CoQs. In addition, in our recent theoretical work related to the new features of electrochemical catalytic reactions [54], we described a new simple voltammetric and time-independent methodology to determine the rate constant of heterogeneous electron transfer step from the features of the electrochemicalcatalytic (EC) mechanism studied in square-wave voltammetry. The synthesis of novel CoQ-based antioxidants will certainly be one of the future challenging tasks in the further experiments with these physiologically important compounds.

\section{Theoretical studies relevant to the coenzyme Q's redox chemistry}

As it has been mentioned at several spots in this review, the redox chemistry of coenzyme Qs proceeds mainly via two electron transfer steps, which can be additionally coupled to one or two protonation steps. Keeping in mind all the possible redox transformations in which CoQs are undergoing in both aprotic or aqueous media [2, 9, 31-47], several relevant theoretical models can be applied to describe their voltammetric behavior. In the last few years, several groups worked on the development of mathematical models of coupled redox reactions under conditions of cyclic and square-wave voltammetry. The theoretical results relevant to the voltammetric behavior of the so-called EE (electrochemical-electrochemical), ECE (electrochemical-chemical-electrochemical), and EECat (electrochemical-electrochemical-catalytic) redox mechanisms under conditions of cyclic staircase voltammetry are comprehensively elaborated in the recent work of Gulaboski et al. [55]. Moreover, the voltammetric features of EEcat [56], CE (chemical-electrochemical) [57], ECE [58], and EC [54] redox mechanisms have also been studied under conditions of square-wave voltammetry by Gulaboski et al. Mirceski et al. [59-61], Lovric and Komorsky-Lovric et al. [62-71], and Molina et al. [72-76] also made several great contributions towards theoretical understanding of the complex voltammetric behavior of coenzyme Qs under various conditions. Several recent review works report on the major achievements in the theory of square-wave and cyclic voltammetry [77-81]. Many of the theoretical features described in [45-66] fit to the experimental voltammetric behavior of the coenzyme Qs. The results of all considered theoretical models provide valuable information about making diagnostic criteria for recognizing particular redox transformation of the CoQs. Additionally, valuable and simple methods are proposed about assessing the kinetic and thermodynamic parameters relevant to each step of CoQ redox transformation [55-81].

\section{Future perspectives}

The number of natural members belonging to the family of coenzyme Q-related compounds is quite impressive [47]. Various important benzoquinones (fumigatin, spinulosin, embelin, rapanone, mesaquinone, rhodoquinone, thymoquinone, mitomycin) naphthoquinones (lawsone, juglone, ramentone, menadion, phthiocol, dunnione, alkanin), and anthraquinones (rhein, emodin, physcion, alizarin, rubiadin, lucidin, purpurin, kermeseic acid) are commonly seen as close relatives to coenzyme Qs. Many of these natural CoQ-like compounds have immense importance in pharmaceutical and chemical industry $[47,82]$. Although there are numerous voltammetric studies already reported on some of these naturally occurring quinones [83], there is still much work to be done in order to recognize much closer the chemical features and the mechanisms of redox transformation of these compounds. For example, even recently it has been recognized that Coenzyme Q10 can undergo structural changes in the presence of the membrane-bound Cytochrome P450 enzyme [42]. That reaction is quite important, since it can lead to modification of the pathway of mitochondrial electron transport chain. It is well known that many of the CoQ relatives mentioned above are seen as potent antioxidants having amphiphilic properties [84]. However, the role of these CoQ-like compounds in the transfer of ions across biological membranes is not well elucidated. Recently, in our laboratory, we performed voltammetric experiments with the compound Embelin (2,5dihydroxy-3-undecyl p-benzoquinone) and we showed that this compound can bind and transfer $\mathrm{Ca}^{2+}$ cations across the liquid-liquid interface between phospholipid-modified 1,2dichlor ethane and water (see Fig. 5). We already reported similar findings with the hydroxyl derivatives of Coenzyme $\mathrm{Q}_{10}[42,45]$. Indeed, these findings are quite relevant, since it can throw a new light towards understanding of novel physiological functions of these compounds. Voltammetry can be a 


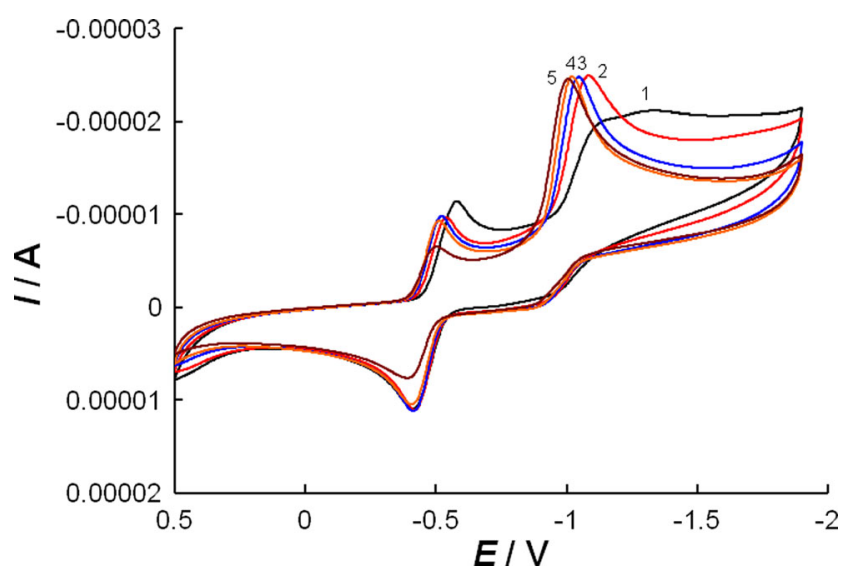

Fig. 5 Three-phase electrode cyclo-voltammetric experiments with Embelin dissolved in 1,2-dichlor ethane (DCE). A droplet of Embelin solution in DCE was attached to the surface of a glassy carbon electrode and immersed in water solutions containing $0 \mathrm{mmol} / \mathrm{L} \mathrm{Ca}^{2+}$ (1), $1 \mathrm{mmol} / \mathrm{L} \mathrm{Ca}^{2+}$ (2), $3 \mathrm{mmol} / \mathrm{L} \mathrm{Ca}^{2+}$ (3), $5 \mathrm{mmol} / \mathrm{L} \mathrm{Ca}^{2+}$ (4), and $10 \mathrm{mmol} / \mathrm{L} \mathrm{Ca}^{2+}(5)$. Shifting of the peak potentials of both peaks by increasing $\mathrm{Ca}^{2+}$ concentration implies complexation reaction between reduced Embelin molecules and the $\mathrm{Ca}^{2+}$ ions. Scan rate was $50 \mathrm{mV} / \mathrm{s}$. Concentration of Embelin dissolved in DCE was $10 \mathrm{mmol} / \mathrm{L}$. (For more details of these experiments, see [85].)

valuable tool to study the interactions of the CoQ-like systems with relevant physiological targets $[59,84,85]$. Not only can it help in revealing their mechanism of actions, but also it can be seen as a tool to measure important kinetic and thermodynamic parameters of those interactions. Indeed, such voltammetric studies will lead to better understanding of the drug-target interactions, and it will be of immense help in the field of drug design. Sabuzi et al. [86] recently reported about a new class of quinoid compounds named KuQuinones. These have a very low reduction potential, and they are characterized by a broad absorption spectrum in the visible region, mainly due to their pentacyclic, highly conjugated structure. The unique properties of these compounds make them promising candidates as sensitive material in constructing photoelectrochemical devices.

Acknowledgments Rubin Gulaboski thanks the Goce Delcev University in Stip, Macedonia, for the financial support via the project: Metal-complexing and antioxidative properties of some new derivatives of Coenzyme Q-0 (2013-2016).

\section{References}

1. Crane FL (1965) In Biochemistry of quinones (Morton RA, Ed.) 183-206, Academic Press New York.

2. Chambers JO (1974) Electrochemistry of quinones in: The chemistry of Quinoid Compounds, Part 1 (Patai S. Ed.) 737-792, John Wiley \& Sons, London.

3. Trumpower BL (1982) Functions of quinones in energy conserving systems. Academic Press, New York

4. Molyneux SL, Young JM, Florkowski CM, Lever M, George PM (2007) Coenzyme Q10: is there a clinical role and a case for measurement? Clin Biochem Rev 29:71-81
5. Sarewicz M, Osyczka A (2015) Electronic connection between the quinone and cytochrome $\mathrm{C}$ redox pools and its role in regulation of mitochondrial electron transfer chain signalling. Physiol Rev 95: 219-243

6. Ebadi M, Marwah J, Chopra R (Eds) (2001) Mitochondrial ubiquinone (Coenzyme Q10) biochemical, functional, medical and therapeutic aspects in human health and diseases, vol 1 and 2, Prominent Press, Scottsdale, Arizona

7. Echtay KS, Winkler E, Klingenberg M (2000) Coenzyme Q10 is an obligatory co-factor for uncoupling protein function. Nature 408:609-613

8. Finkel T (1998) Oxygen radicals and signalling. Cell Biol 10:248-253

9. Cauquis G, Marbach G (1971) Biological aspects of electrochemistry (Milazzo G, Jones PE, Rampazzo L, Eds), Springer

10. Sasaki K, Kashimura T, Ohura M, Ohsaki Y, Ohta N (1990) Solvent effect in the electrochemical reduction of p-quinones in several aprotic solvents. J Electrochem Soc 137:2437-2443

11. Morton RA (1965) Biochemistry of quinones. Academic Press, New York

12. Chambers JQ (1988) Electrochemistry of quinones, in The Chemistry of Quinonoid Compounds, S. Patai and Z. Rappoport, Eds. 2:719-757, Wiley, New York, NY, USA, 1988

13. Laviron E (1986) Electrochemical reactions with protonations at equilibrium. Part XIII. Experimental study of the homogeneous electron exchange in quinone/dihydroquinone systems. J Electroanal Chem 208:357-372

14. Russel C, Jaenicke J (1986) Heterogeneous electron exchange of quinones in aprotic solvents. Part III. The second reduction step of p-benzoquinone and its dependence on the supporting electrolyte. J Electroanal Chem 199:139-151

15. Michalkiewicz S (2007) Cathodic reduction of coenzyme $\mathrm{Q}_{10}$ on glassy carbon electrode in acetic acid-acetonitrile solutions. Bioelectrochem 70:495-500

16. Michalkiewicz S (2011) Anodic oxidation of oxidized forms of coenzyme Q10 AND Q0 on carbon electrodes in acetic acid solutions. Bioelectrochem 82:103-111

17. Petrucci R, Giorgini E, Damiani E, Carloni P, Marrosu G, Trazza A, Paolo G (2000) A study of the interactions between coenzyme Q0 and superoxide anion. Could ubiquinones mimic superoxide dismutase (SOD)? Res Chem Intermed 26:269-282

18. Cauquis G, Marbach G (1971). The redox behaviour of biological quinines and its relation with the mitochondrial respiratory chain. Biological aspects of electrochemistry (Milazzo G et al., Eds) 18: 205-214

19. Biondi C, Galeazzi R, Littarru G, Greci L (2002) Reduction of 1,4quinone and ubiquinones by hydrogen atom transfer and UVA radiation. Free Radic Res 36:399-404

20. Mukai K (2001). Free radical chemistry of coenzyme Q In Coenzyme Q: molecular mechanisms in health and disease, Kagan VE, Quinn PJ (Eds) CRC Press London New York

21. Itoh S, Kawakami H, Fukuzumi S (1998) Electrochemical behavior and characterization of semiquinone radical anion species of coenzyme PQQ in aprotic organic media. J Am Chem Soc 120:7271-7277

22. Turkowicz MJ, Karpinska J (2013) Analytical problems with the determination of coenzyme Q10 in biological samples. BioFactors 39:176-185

23. Petrova EV, Korotkova EI, Kratochvil B, Vornova OA, Dorozhko EV, Bulycheva EV (2014) Investigation of Coenzyme Q10 by voltammetry. Procedia Chem 10:173-178

24. Lemmer C, Bouvet M, Meunier-Prest R (2011) Proton coupled electron transfer of ubiquinone Q2 incorporated in a selfassembled monolayer. Phys Chem Chem Phys 13:13327-13332

25. Marchal D, Boireau W, Laval JM, Moiroux J, Bourdillon C (1997) An electrochemical approach of the redox behavior of water insoluble ubiquinones or plastoquinones incorporated in supported phospholipid layers. Biophys J 72:2679-2687 
26. Weiss SA, Jeuken LJC (2009) Lipid-membrane modified electrodes to study quinine oxidoreductases. Biochem Soc Trans 37:1-11. doi: 10.1042/BST0370707

27. Contin M, Flor S, Martinefski M, Lucangioli S, Tripodi V (2014) New analytical strategies applied in the determination of Coenzyme Q10 in biological matrix in advanced protocols in oxidative stress III. Methods Mol Biol 1208:409-420, Springer Science and Business Media, New York

28. Ru J, Du J, Qin D-D, Huang B-M, Xue Z-H, Zhou X-B, Lu X-Q (2013) An electrochemical glutathione sensor: ubiquinone as a transducer. Talanta 11:15-20

29. Martensson C, Agmo Hernandez V (2012) Ubiquinone-10 in goldimmobilized lipid membrane structures acts as a sensor for acetylcholine and other tetraalkylammonium cations. Bioelectrochem 88: 171-180

30. Saleh Ahammad AJ, Lee J-J, Aminur Rahman MD (2009) Electrochemical sensors based on carbon nanotubes. Sensors 9: 2289-2319

31. Emons H, Wittstock G, Voigt B, Seidel H (1992) Voltammetry trace determination of ubiquinones at mercury electrodes. Fresenius $\mathrm{J}$ Anal Chem 342:737-739

32. Gordillo GJ, Schiffrin DJ (1994) Redox properties of Ubiquinon (UQ10) adsorbed on a mercury electrode. J Hem Soc Faraday Trans 90:1913-1922

33. Dryhurst D, Kadish KM, Scheller F, Renneberg R (1982) Biological electrochemistry. Academic Press, Paris, Tokyo

34. Meisel D, Fessenden RW (1976) Electron exchange and electron transfer of semiquinones in aqueous solutions. J Am Chem Soc 98: $7505-7510$

35. Kahlert H (2008) Functionalized carbon electrodes for $\mathrm{pH}$ determination. J Solid State Electrochem 12:1255-1266

36. Shi K, Shiu K-K (2004) Adsorption of some quinone derivatives at electrochemically activated glassy carbon electrodes. J Electroanal Chem 574:63-70

37. Bard AJ, Faulkner LR (200) Electrochemical Methods, John Wiley \& Sons, 2nd edition

38. Shim YB, Park SM (1997) Spectroelectrochemical studies of pbenzoquinone reduction in aqueous media. J Electroanal Chem 425:201-207

39. Gómez M, González FJ, González I (2003) A model for characterization of successive hydrogen bonding interactions with electrochemically generated charged species. The quinone electroreduction in the presence of donor protons. Electroanal 15: 635-645

40. Eggins BR, Chambers JQ (1970) Proton effects in the electrochemistry of the quinone hydroquinone system in aprotic solvents. $\mathrm{J}$ Electrochem Soc 117:186-192

41. Quan M, Sanchez D, Wasylkiw MF, Smith DK (2007) Voltammetry of quinones in unbuffered aqueous solution: reassessing the roles of proton transfer and hydrogen bonding in the aqueous electrochemistry of quinones. J Am Chem Soc 129:12847-12856

42. Bogeski I, Gulaboski R, Kappl R, Mirceski V, Stefova M, Petreska J, Hoth M (2011) Calcium binding and transport by Coenzyme Q. J Am Chem Soc 133:9293-9303

43. Gulaboski R, Bogeski I, Mirceski V, Saul S, Pasieka B, Haeri HH, Stefova M, Petreska Stanoeva J, Mitrev S, Hoth M, Kappl R (2013) Hydroxylated derivatives of dimethoxy-1,4-benzoquinone as redox switchable earth-alkaline metal ligands and radical scavengers. Sci Reports 3:1-8. doi:10.1038/srep01865

44. Katsumi J, Nakayama T, Esaka Y, Uno B (2012) mechanistic study of the electrochemical reduction of 9,10-anthraquinone in presence of hydrogen-bond and proton donating additives. Anal Sci 28:257-265

45. Mirceski V, Gulaboski R, Bogeski I, Hoth M (2007) Redox chemistry of Ca-transporter 2-palmitoylhydroquinone in an artificial thin organic film membrane. J Phys Chem C 111:6068-6076
46. Valerian EK, Quinn PJ (2001) Coenzyme Q: molecular mechanism in health and disease. CRC Press, New York

47. Hohl H (1986) Quinones in biology: functions in electron transfer and oxygen activation. Adv Free Radical Biol Med 2:211-279

48. Littarru GP, Tiano L (2007) Bioenergetic and antioxidant properties of Coenzyme Q10: recent developments. Mol Biotechnol 37:31-37

49. Halliwell B, Gutteridge JMC (2007) Free radicals in biology and medicine, 4th edn. New York, Oxford

50. Crane FL (2007) Discovery of ubiquinone (coenzyme Q) and an overview of function. Mitochondrion 7S:S2-S7

51. Acton A (2013). Enzymes and coenzymes-advances in research and application. ScholaryEditions Atlanta Gerogia

52. Dhanasekaran M, Ren J (2005) The emerging role of coenzyme Q-10 in aging, neurodegeneration, cardiovascular disease, cancer and diabetes mellitus. Curr Neurovasc Res 2:447-459

53. Miyadera H, Kano K, Miyoshi H, Ishii N, Hekimi S, Kita K (2002) Quinones in long-lived clk-1 mutants of Caenorhabditis elegans. Febs Lett 512:33-37

54. Gulaboski R, Mirceski V (2015) New aspects of the electrochemicalcatalytic (EC') mechanism in square-wave voltammetry. Electrochim Acta 167:219-225

55. Gulaboski R, Kokoskarova P, Mitrev S (2012) Theoretical aspects of several successive two-step redox mechanisms in protein-film cyclic staircase voltammetry. Electrochim Acta 69:86-96

56. Gulaboski R, Mihajlov L (2011) Catalytic mechanism in successive two-step protein-film voltammetry-theoretical study in squarewave voltammetry. Biophys Chem 155:1-9

57. Gulaboski R, Mirceski V, Lovric M, Bogeski I (2005) Theoretical study of a surface electrode reaction preceded by a homogeneous chemical reaction under conditions of square-wave voltammetry. Electrochem Commun 7:515-522

58. Gulaboski R (2009) Surface ECE mechanism in protein film voltammetry - a theoretical study under conditions of square-wave voltammetry. J Solid State Electrochem 13:1015-1024

59. Mirceski V, Komorsky-Lovric S, Lovric M (2007). Square-wave voltammetry: theory and application: In Scholz F (ed) Monographs in Electrochemistry, Springer, Berlin

60. Mirceski V, Gulaboski R (2002) A theoretical and experimental study of a two-step quasireversible surface redox reaction by square-wave voltammetry. Croat Chem Acta 76:37-48

61. Mirceski V, Guziejewski D, Gulaboski R (2015) Electrode kinetics from a single square-wave voltammogram. Maced J Chem Chem Eng 34:36-42

62. Lovric M (1988) The theory of EE mechanism with adsorption of the intermediate. J Electroanal Chem 153:1-27

63. Lovric M, Jadresko D, Komorsky-Lovric S (2013) Theory of square-wave voltammetry of electrode reaction followed by the dimerization of the product. Electrochim Acta 90:226-331

64. Komorsky-Lovric S, Lovric M (2012) Theory of square-wave voltammetry of two electron reduction with the intermediate that is stabilized by complexation. Electrochim Acta 69:60-64

65. Lovric M (2010) Square-wave voltammetry in: Electroanalytical methods (Scholz F, Ed.) Springer, Berlin, 121-145

66. Komorsky-Lovric S, Lovric M (2012) Simulation of square-wave voltammograms of three-electron redox reaction. Electrochim Acta 56:7189-7193

67. Komorsky-Lovric S, Lovric M (1980) Simple EEE mechanism at DME. J Electroanal Chem Interfacial Electrochem 112:169-174

68. Komorsky-Lovric S, Lovric M (2014) Square-wave voltammetry of two step electrode reaction. Int J Electrochem Sci 9:435-444

69. Lovric M, Komorsky-Lovric S (2012) Theory of square-wave voltammetry of kinetically controlled two-step electrode reactions. Croat Chem Acta 85:569-575

70. Komorsky-Lovric S, Lovric M (2013) Theory of square-wave voltammetry of two electrode reactions coupled by reversible chemical reaction. Anal Bioanal Electrochem 5:291-304 
71. Lovric M, Komorsky-Lovric S (2011) Theory of square-wave voltammetry of two-step electrode reaction using an inverse scan direction. Int J Electrochem vol. 2011. http://dx.doi.org/10.4061/2011/ 538341

72. Serna C, Molina A, Moreno MM, Lopez-Tenez M (2005) Study of multistep electrode processes in double potential step techniques at spherical electrodes. J Electroanal Chem 546:97-108

73. Lopez-Tenes M, Moreno MM, Serna C, Molina A (2002) Study of an EE mechanism using double potential step techniques. J Electroanal Chem 528:159-169

74. Serna C, Lopez-Tenez M, Gonzalez J, Molina A (2001) Reversible multistep electrode processes. Consideration of the bulk presence of intermediate species and of the values of the diffusion coefficients in voltammetry. Electrochim Acta 46:2699-2709

75. Laborda E, Martinez-Ortiz F, Molina A (2010) Study of electrochemical processes with coupled homogeneous chemical reaction in differential pulse voltammetry at spherical electrodes and microhemispheres. Electroanal 22:1857-1866

76. Lopez-Tenez M, Gonzalez J, Molina A (2015) Two-electron transfer reactions in electrochemistry for solution-soluble and surfaceconfined molecules: a common approach. J Phys Chem C 118: 12312-12324

77. Gulaboski R, Mirceski V, Bogeski I, Hoth M (2011) Protein film voltammetry: electrochemical enzymatic spectroscopy. A review on recent progress. J Solid State Electrochem 16: $2315-2328$
78. Mirceski V, Gulaboski R, Lovric M, Bogeski I, Kappl R, Hoth M (2013) Square-wave voltammetry: a review on recent progress. Electroanal 25:2411-2422

79. Mirceski V, Gulaboski R (2014) Recent achievements in square-wave voltammetry (a review). Maced J Chem Chem En 33:1-12

80. Laborda E, Gonzalez J, Molina A (2014) Recent advances on the theory of pulse techniques. A mini review. Electrochem Commun 43:25-30

81. Batchelor-McAuley C, Kätelhön E, Barnes EO, Compton RG, Laborda E, Molina A (2015) Recent advances in voltammetry. ChemistryOpen 4:224-260

82. Lenaz G (1985) Coenzyme Q: Biochemistry, bioenergetics and clinical application of ubiquinone, Jihn Willey\&Sons

83. Guin PS, Das S, Mandal PC (2011) Electrochemical reduction of quinones in different media. A review. Int J Electrochem vol. 2011. doi:10.4061/2011/816202

84. James AM, Smith RAJ, Murphy MP (2004) Antioxidant and prooxidant properties of mitochondrial Coenzyme Q. Arch Biochem Biophys 423:47-56

85. Scholz F, Schroeder U, Gulaboski R. Domenech Carbo A (2015) Electrochemistry of immobilized particles and droplets, Experiments with three phase electrodes, 2nd Edition. Springer, Berlin

86. Sabuzi F, Armuzza V, Conte V, Floris B, Venanzi M, Galloni P, Gatto E (2016) KuQuinones: a new class of quinoid compounds as photoactive species on ITO. J Mat Chem C 4:622-629 